\title{
A New Technique of Mastopexy for Mastoptosis: With the Upturned Glandular Flap
}

\author{
Jian $\mathrm{H}^{1 *}$, Xiao Jun $\mathrm{S}^{2}$, Bo T${ }^{3}$, Xiao Xia $\mathrm{L}^{1}$ and Xiong Yu Z1 \\ ${ }^{1}$ Department of Plastic and Beauty Surgery, WuXi Maternal \& Child Health Hospital \\ Affiliated With Nanjing Medical University, China \\ ${ }^{2}$ Department of Plastic Surgery, Wuxi Ninth People's Hospital, Affiliated to Soochow \\ University, China \\ ${ }^{3}$ Wuxi Shangmei Plastic and Beauty Hospital, China
}

*Corresponding author: He Jian, Department of Plastic and Beauty Surgery, WuXi Maternal \& Child Health Hospital Affiliated With Nanjing Medical University, China, Email: hj66126@126.com

\section{Abstract}

A new surgical procedure was introduced for correction of moderate mammary ptosis in this paper. The double-ring incision around areola was taken, tongue-shaped gland flap at the lower part of breast was turned over and filled in the posterior space of breast. The glands at both sides of the lower part were sutured together, and the basal part of the breast was tighten fully. Then, the upper pole gland was sutured by raising so that the nipple-areola complex is fully raised. The breasts were conical through this shaping, thus the correction effect of breast ptosis was satisfactory. This technique is ingenious in design, convenient in operation and exact in curative effect. It can be used as one of the options for mastopexy.

Keywords: Mastoptosis; Mastopexy; Glandular flap

\section{Background}

The mastopexy is one of the common surgeries in breast plastic surgery. There are many kinds of conventional surgeries for the breast ptosis. The perfect surgical results are difficult to obtain, due to the influence of many factors such as type of ptosis, degree of ptosis, age, tissue elasticity, etc. Although there were many reports on correcting mastoptosis, most of them were aimed at breast dysplasia or breast hypertrophy in the past. There were few reports on correcting breast ptosis with normal development and proper volume. In order to obtain better surgical results, the author designed a new technique with the tongue-shaped breast tissue flap to correct moderate breast ptosis in normal volume without no need for mesh or any other foreign material. After the preliminary experience was obtained, the professional report was carried out once [1]. We have continued to perform this kind of operation together with plastic surgeons in other hospitals in recent years. The further improvements have been made to this technology. We believe that it is more satisfactory and stable in correcting moderate mastoptosis with this special technology. This method has better practical value and spreading value.

The appearance and shape of the breasts are the very important for women. The necessary conditions for breast fullness and good projection plump breasts are: appropriate tissue volume, sufficient tissue density and elasticity, and strong support structure. Breast ptosis is perceived as unattractive and thus is one of the common reasons for the presentation of women to the plastic 


\section{International Journal of Transplantation \& Plastic Surgery}

surgeon [2]. There were loose skin, atrophy and soft of glands, downward movement of nipple areola, and overall breast flatness in the drooping breast. These problems can be effectively solved by appropriate mastopexy technique. The purpose of a mastopexy is to restore the perfect shape and volume of the breast. This will improve the patient's quality of life and her self-confidence will be regained.

\section{Patients and Methods}

\section{Patients}

The introduced corrective method is suitable for healthy slender who have moderate breast ptosis, thick elastic skin and large areola, normal volume and cannot use implants. From October 2008 to May 2019, 20 patients underwent mastopexy. The patients, aged 31-40 years old, were married and had children. All of them were dissatisfied with their breasts appearance and demanded improvement the breast shape. Breast volume is $200 \sim 420 \mathrm{ml}$, with an average of $338 \mathrm{ml}$ in the patients. The distance between the lower pole of the breast and the lower plica is $2.0 \sim 3.5 \mathrm{~cm}$. Using Regnault's Classification [3], they are all moderately ptosis. Those cases with mastopexy were performed in this way, with a mean follow-up of 18 months. Patients and the surgeon have expressed satisfaction with the procedure (Figures $1 \mathrm{a}, 1 \mathrm{~b}$ \& 1c).

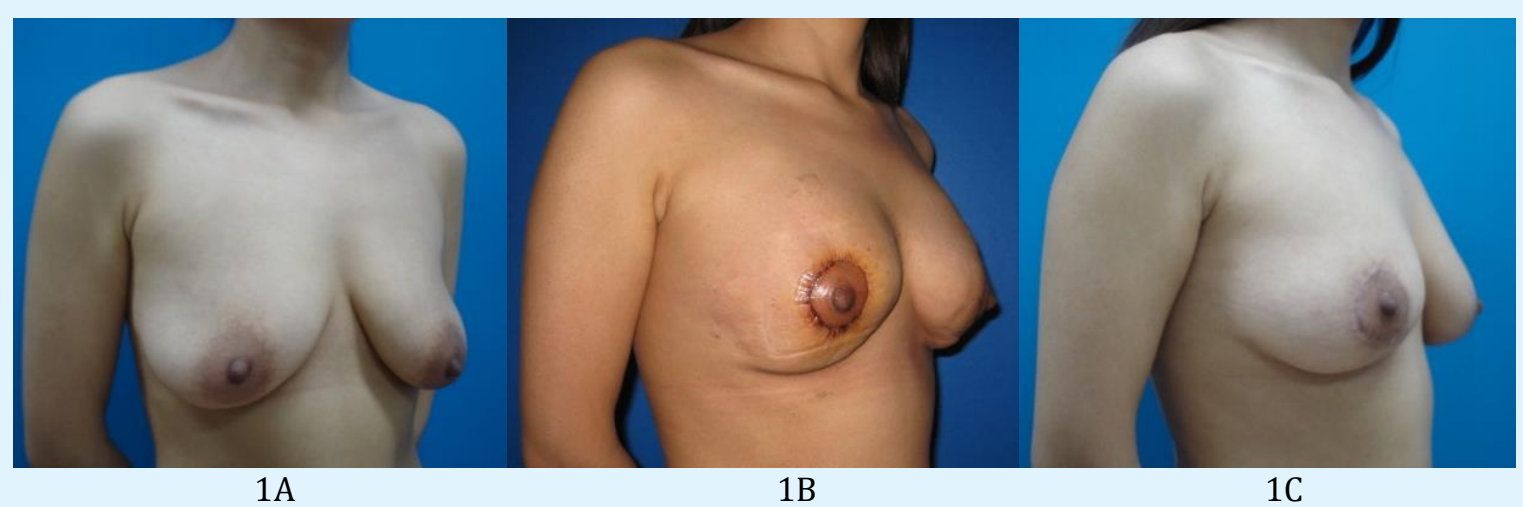

Figure 1A: preoperative, Figure 1B: 10 days postoperation, Figure 1C: 16 months postoperation.

\section{Anesthesia}

The tumescent anesthesia was used for all patients. Ingredients of swelling liquid includes: $350 \mathrm{ml}$ of $0.9 \%$ Sodium Chloride Injection, $25 \mathrm{ml}$ of $2 \%$ Lidocaine Hydrochloride Injection, $25 \mathrm{ml}$ of $0.5 \%$ Bupivacaine Hydrochloride Injection, and $0.5 \mathrm{ml}$ of $0.1 \%$ Epinephrine Hydrochloride Injection.

\section{Surgical Technique}

1. Double ring incision around areola was designed with the "round block" technique [4]. The epidermis between the inner and outer ring incisions is removed, and the skin of the outer ring incision was cut except the upper inner part (about width of 3-4 cm) (Figure 2A).

2. The blunt and sharp peeling is performed on the gland surface.
3. Two longitudinal incisions are made in the lowest of mammary gland, and tongue shaped breast tissue flap was make (Figure 2B).

4. The tongue-shaped glandular flap was upturned and inserted into the posterior mammary space, and sutured and fixed (Figure 2C).

5. The gland tissues on both sides of the lower part are directly drawn and sutured to fully reduce the length of the breast base (Figure 5).

6. A longitudinal incision is made in the middle of the upper breast tissue, and the lowest point of the incision is sewn to the highest point to form a transverse closure (Figure 7), so as to effectively lift the NAC.

7. The ring incision around areola was sutured with the "round block" technique. 


\section{International Journal of Transplantation \& Plastic Surgery}

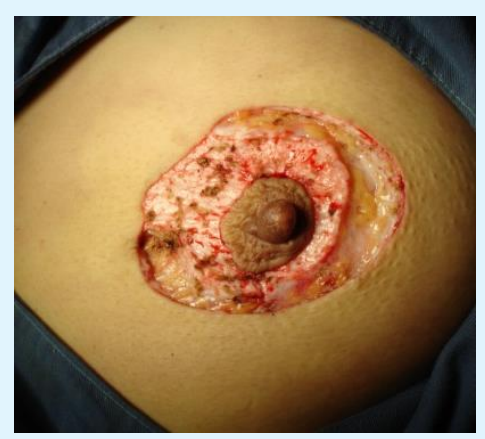

$2 \mathrm{~A}$

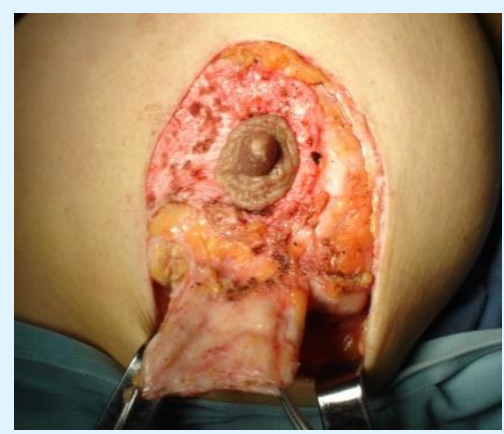

2B

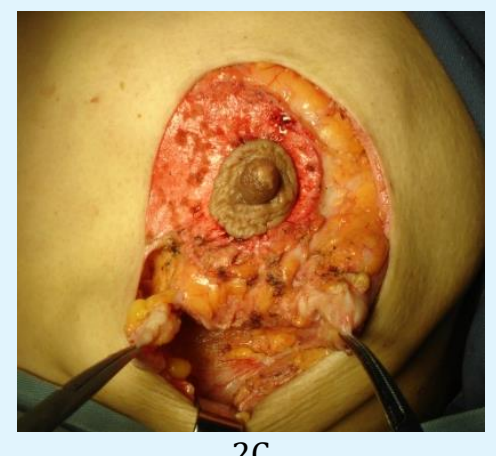

2C

Figure 2A: Periareolar double-ring incision and epidermis removal, Figure 2B: Tongue-shaped breast tissue flap was make, Figure 2C: The tongue-shaped glandular flap was upturned into the posterior mammary space.

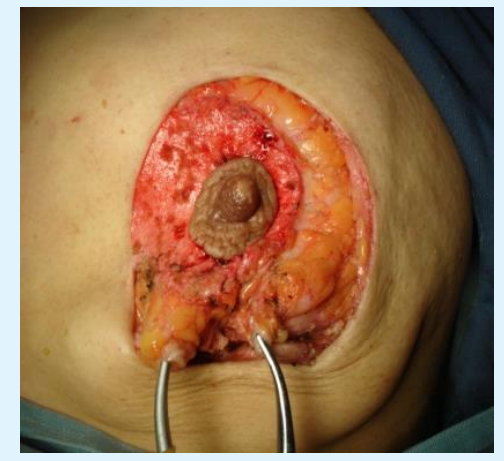

$3 \mathrm{~A}$

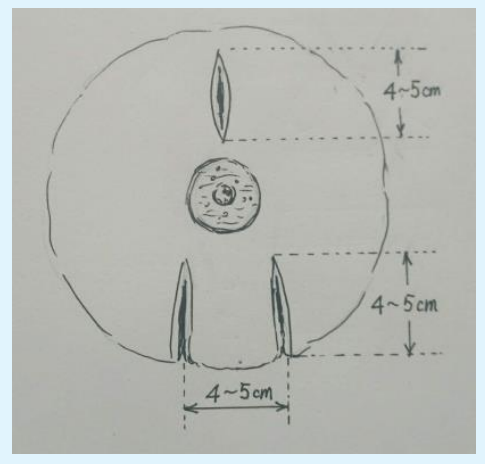

3B

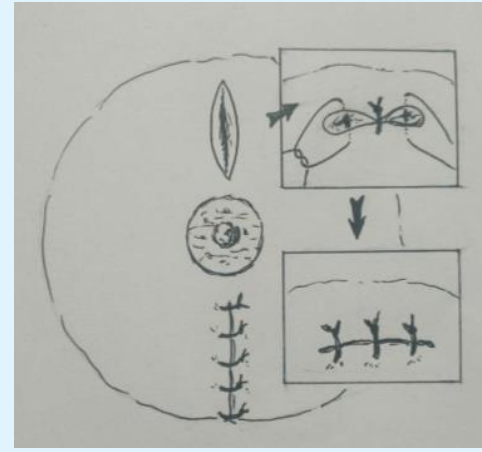

$3 \mathrm{C}$

Figure 3A: Suture of lower gland tissue, Figure 3B: Diagram of incision of mammary tissue. Figure 3C: diagram of gland suture.

\section{Discussion}

The ideal effect of mastopexy should be: The breast had good shape and bilateral symmetry; The nipple areola feels good; Retention of breast elasticity and good skin tension; The incision is concealed and the scar is less; It's not easy to relapse. In general, the breast ptosis is divided into the following groups [5]: 1 - Mastoptosis with breast hypertrophy. 2 - Mastoptosis with breast hypotrophy. 3 Mastoptosis with breast normotrophy. The corrective techniques chosen are different according to the various types of ptosis. The breast reduction with resection of glandule mammary tissues was made in the patients of the first groups. In the second group the augmentative mammaplasty took place. The mastopexy or/and augmentative will be chosen in the third group patients.
Its correction by mastopexy presents one of the greatest challenges to the breast surgeon aiming at a pleasant full conical shape and stability of the results [6]. In order to achieve a projection and fullness effect, implants are a more common and effective method. However, the mastopexy with or without the use of implants being indicated, several considerations have to be taken into account: the wishes of the patient, age of the patient, degree of ptosis, parenchymal volume, covering tissue, quality of the tissue, pocket implant, and resulting scars etc [7]. For normally volume breasts, the addition of breast prostheses will inevitably result in a too large of the breast volume after surgery, increasing the chance of drooping again.

Skin resection, repositioning of the nipple-areolar complex (NAC) and gland recombination are the key steps for successful breast fixation [8]. Current mastopexy 


\section{International Journal of Transplantation \& Plastic Surgery}

techniques rely on incisions on the breast to correct ptosis. Trading a ptotic breast for a visibly scarred breast can be a difficult choice [9]. Initially, simple crescentshaped incisions were used for mastopexy. After technical improvement by many plastic surgeons, some different incisions have been gradually developed, for example $\mathrm{T}$ incision and a vertical incision [10], concentric round incision [4], Y-shaped incision [11], fish-shaped incision [12], L-shaped incision [13] and so on. There are three currently accepted skin patterns used for mastopexy: wise or $\mathrm{T}$ pattern, vertical and concentric [14]. In the main, skin incisions are usually selected by both the doctor and the patient. The patient's willingness is even greater. Concentric round incisions around the areola become the first choice for many patients in recent years. The increasing demand for minimum scar techniques has led to wider use of periareolar approaches for breast manipulation [15].

In general, the position of the NAC is critically important to the aesthetic appearance of the breast. In the case of ptotic breast, the severity of the ptosis is evaluated according to the position of the nipple in relation to the inframammary fold [16]. The NAC was relocated to its proper position by depending on changes in the skin incision and the reorganization of the glands. The method of lifting the NAC by skin incision alone is not very effective in the long term. For the effective and stable lifting of the NAC, the remolding of the glands is the most critical.

The reorganization of glands is the most important step in mastopexy. The reorganization method is mostly decided by the plastic surgeon. Early methods were mostly simple glandular sutures, but were phased out due to poor results. Later, many technology were developed, such as glandular rotation overlapping technology [17], double-flap technology [18], triple flaps procedure [6], Zshaped tissue flap transfer [19], gland stacked technique [20] etc. These techniques are all shaped by the transfer and redistribution of breast tissue and recombination with wise or $\mathrm{T}$ pattern, vertical incisions. Larger incision scars are their obvious disadvantage.

In order to effectively solve the problems of skin resection, the NAC repositioning and gland recombination, we developed a new method for mastopexy. The tongue-shaped gland flap of the lower part of the breast is made in the concentric round incision. Then the tissue flap is upturned for $180^{\circ}$ and filled into the posterior clearance of the breast. For the sake of overcoming the shortcomings of the large base of the breast and the overall flatness of the breast in the periareal incision, a special procedure must be completed. It is that a firm suture of the glands on both sides of the lower part should be made.

The upper glands are usually significantly elongated in the breast ptosis. At first, we tightened the upper gland by rotating the gland flap. Experience has shown that the NAC's lifting effect was not obvious with this method. After improvement, a longitudinal incision was made in the upper gland, and then the lateral suture was performed so that the length of the upper gland was immediately shortened. After such treatment, the NBC's lifting was more secure. The main technical points of this procedure: shorten the upper breast length, fill the middle of the breast and reduce the breast circumference. This technique provides a good projection and fullness without the need for implants. The results were stable in the long term.

\section{Conclusion}

For mastoptosis with normal volume breast, satisfactory surgery results can be achieved through the recombination of breast tissue and the tightening of the lower pole without placing the prosthesis. The design is ingenious, operation easily, flexible, natural breast shape after surgery, and the effect is accurate for the method of correcting mammary ptosis with tongue tissue flap. It is a safe, effective technique, with high predictability, a low complication rate, reliable effect and high patient satisfaction. This surgery approach provides a new stratagem for correcting mastoptosis.

\section{References}

1. He Jian, Liu Xiao Xia (2018) Correction of moderate mastoptosis with the upturned glandular flap. Chinese Journal of Plastic Surgery 34(6): 453-457.

2. Bogdanov-Berezovsky A, Pagkalos VA, Krieger Y, Shoham Y, Silberstein E (2013) Burying the knot in periareolar mastopexy. Aesthetic Plast Surg 37(4): 851-853.

3. Regnault P (1976) Breast ptosis. Definition and treatment. Clin Plast Surg 3(2): 193-203.

4. Benelli L (1990) A new periareolar mammaplasty: the "round block" technique. Aesth Plast Surg 14(2): 93100. 


\section{International Journal of Transplantation \& Plastic Surgery}

5. Dobriakova OB, Dobriakov BS, Goulev VS (2005) Our experience of mastoptosis correction. J Cosmet Surg French 29(3): 15-22.

6. Gheita A, Moftah A (2011) Breast ptosis managed by mastopexy using the triple flaps procedure. Aesth Plast Surg 35(1): 107-115.

7. De Benito J, Sánchez K (2010) Key points in mastopexy. Aesthetic Plast Surg 34(6): 711-715.

8. Hall-Findley EJ (2002) Pedicles in vertical breast reduction and mastopexy. Clin Plast Surg 29(3): 379391.

9. Mahabir RC, Zamboni WA (2008) A new technique of internal suture mastopexy for mild to moderate breast ptosis. Can J Plast Surg 16(1): 11-13.

10. Lassus C (1999) Update on vertical mammaplasty. Plast Reconstr Surg 104: 2289-2304.

11. Hidalgo D (2007) Y-scar vertical mammaplasty. Plast Reconstr Surg 120(7): 1749-1754.

12. Doft MA, Hardy KL, Ascherman JA (2012) The "fish" mastopexy. Plast Reconstr Surg 129(5): 865-866.

13. Rohrich RJ, Thornton JF, Jakubietz RG, Jakubietz MG, Grünert JG (2004) The limited scar mastopexy: current concepts and approaches to correct breast ptosis. Plast Reconstr Surg 114(6): 1622-1630.
14. Hickman DM (2011) Application of the Goes doubleskin peri-areolar mastopexy with and without implants: A 14-year experience. J Plast Reconstr Aesthet Surg 64(2): 164-173.

15. Schleich AR, Black DM, McCraw JB (2010) The aesthetic correction of the ptotic breast by the procedure of nipple-areola transposition: a contemporary translation and commentary. J Plast Reconstr Aesthet Surg 63(7): 1136-1141.

16. Regnault P (1966) The hypoplastic and ptotic breast: a combined operation with prosthetic augmentation. Plast Reconstr Surg 37(1): 31-37.

17. Erol O, Spira M (1980) A mastopexy technique for mild to moderate ptosis. Plast Reconstr Surg 65(5): 603-609.

18. Foustanos A, Zavrides H (2007) A double-flap technique: an alternative mastopexy approach. Plast Reconstr Surg 120(1): 55-60.

19. Singh DP, Forte AJ, Apostolides JG, Zahiri HR, Stromberg J, et al. (2011) Z-mammaplasty: a novel concept in mastopexy. Eplasty 11(e29): 260-269.

20. Kelemen N, Kannan RY, Offer GJ (2013) A stacked technique of mastopexy: volume redistribution mastopexy with inferior flap and superomedially based pedicle. Aesthet Plast Surg 37(2): 349-353. 